http://dx.doi.org/10.5007/1981-1322.2017v12n1p37

\title{
Malba Tahan, seus conceitos presentes na atualidade
}

\author{
Malba Tahan, its concepts present in the current
}

Liceia Alves Pires

liceia.pires@unespar.edu.br

Adrieli Apolinário

adrieli_apolinario@hotmail.com

\begin{abstract}
Resumo
Professores de matemática preocupados com a aprendizagem de seus alunos estão sempre em busca de novas metodologias que facilitem o processo de aprendizagem, principalmente aqueles que atuam com alunos de Sala de Apoio, onde os alunos que as frequentam, apresentam grandes dificuldades de entendimento dos conteúdos matemáticos. Assim sendo, o presente artigo busca relatar uma pesquisa e uma intervenção pedagógica em uma sala de apoio a aprendizagem, realizada com o objetivo de apresentar as ideias de Malba Tahan e sua prática docente como um instrumento para ajudar no trabalho do professor. Para alcançar este objetivo foi realizado um questionário com professores de matemática da rede Estadual de Ensino do Litoral paranaense, com o intuito de verificar quais os conhecimentos do mesmo sobre o trabalho de Malba Tahan e na sequência foram aplicados alguns métodos propostos pelo autor em uma turma de Sala de apoio do Colégio Estadual Rocha Pombo, para verificar se eles são realmente eficazes. Dentre os resultados obtidos, destaca-se o baixo índice de professores que conhecem as ideias de Malba Tahan sobre o ensino de matemática e a eficácia desses métodos para minimizar a dificuldade na aprendizagem dos alunos.
\end{abstract}

Palavras-chave: Metodologia de ensino; Malba Tahan; Sala de apoio.

\begin{abstract}
Mathematics teachers concerned with the learning of their students are always in search of new methodologies that facilitate the learning process, especially those that work with students of the Support Room, where the students who attend them, present great difficulties of understanding the mathematical contents . Thus, this article seeks to report a research and a pedagogical intervention in a learning support room, with the aim of presenting the ideas of Malba Tahan and his teaching practice as an instrument to help in the work of the teacher. In order to reach this objective, a questionnaire was carried out with teachers of mathematics of the State Teaching Network of the Coast of Paraná, in order to verify the knowledge of the same about the work of Malba Tahan and in the sequence were applied some methods proposed by the author in a class Of Room of support of the State School Rock Pombo, to verify if they are really effective. Among the obtained results, the low index of teachers who know the ideas of Malba Tahan on the teaching of mathematics and the effectiveness of these methods to minimize the difficulty in the learning of the students stands out.
\end{abstract}

Key-words: Teaching methodology; Malba Tahan; Support room.

\section{INTRODUÇÃO}

A matemática é uma das matérias mais temidas pelos estudantes e que menos lhes chama a atenção. Os professores da disciplina estão sempre em busca de alternativas que ajudem a alcançar um ensino mais eficiente e assim despertar o interesse do aluno, principalmente aqueles professores que trabalham com alunos que apresentam muitas dificuldades e grandes defasagens. 
Esse contexto justifica a realização deste estudo, que apresenta a didática utilizada pelo professor Júlio César de Mello e Souza (1895 - 1974) mais conhecido pelo pseudônimo de Malba Tahan em suas aulas, como uma ferramenta a ser utilizada por professores de matemática que buscam uma melhoria no ensino da disciplina.

O objetivo dessa pesquisa é apresentar a didática de Malba Tahan e as metodologias que ele utilizava em suas aulas, como uma ferramenta a ser utilizada por professores que atuam em salas de apoio a aprendizagem de matemática.

Deseja-se destacar a importância de Malba Tahan para além do aspecto literário, abordando esses outros pontos pouco conhecidos deste professor brasileiro.

\subsection{BIOGRAFIA DE JÚLIO CÉSAR DE MELLO E SOUZA: A TRAJETÓRIA DE UM PROFESSOR-AUTOR}

Júlio César de Mello e Souza nasceu em 06 de maio de 1895 na cidade do Rio de Janeiro. Teve como pais João de Deus de Mello e Souza e Carolina Carlos de Toledo, ambos professores. Sua família paterna era natural de Alcobaça, Portugal e veio para o Brasil por volta de 1755. Com o falecimento de seu avô, Comendador Francisco José de Mello e Souza, a família enfrentou uma crise financeira, que obrigou João de Deus de Mello e Souza e seus irmãos a abandonar os estudos e começar a trabalhar para manter a família. (FARIA, 2004, p. 17-18)

Ainda muito pequeno, Júlio César mudou-se com a família para a cidade Queluz-SP, onde passou sua infância, até alcançar a idade de ingressar no colégio militar. Seu irmão mais velho, João Batista de Melo e Souza, ficou encarregado de prepará-lo para o exame de admissão.

Em 1906 Júlio Cesar despede-se de sua infância em Queluz e volta para o Rio de Janeiro para estudar no Colégio Militar, atendendo a vontade de seu pai. Seus pais aproveitam a sua ausência e fazem o que ele denominou de "sapotagem": jogam sua coleção de sapos no rio, deixando-o muito desapontando e lhe causando grande tristeza. Depois deste episódio, Júlio César continuou sua coleção de sapos, só que desta vez colecionava réplicas feitas de madeira, louça, metal, jade e cristal (FARIA, 2004, p. 26).

Após três anos, em 1909, em função da pequena renda familiar ele não consegue dar continuidade aos seus estudos no Colégio Militar é transferido para o Colégio Pedro II onde estudou em regime de internato, podendo sair apenas aos finais de semana para visitar uma tia. 
Nessa época Júlio César não tinha muito gosto pelos números, seu boletim registrou vermelhos em álgebra e aritmética. Por outro lado, Júlio já mostrava talento para escrever, e até vendia redações para seus colegas de classe.

Ainda em sua infância, elaborou sua primeira obra, um manuscrito, com apenas um exemplar, e batizou com o nome de ERRE. A origem do nome é um mistério, não se sabe se é do verbo errar ou do nome da letra $\mathrm{R}$.

A juventude de Júlio César foi marcada pelos estudos e pelo início de sua vida profissional. No Colégio Pedro II, ainda como estudante, começou a trabalhar como auxiliar na Biblioteca Nacional do Rio de Janeiro. Nessa mesma época, ele optou pelo curso de Magistério para professor primário na Escola Normal do Distrito Federal, e começou a lecionar para turmas suplementares do externato do Colégio Pedro II.

Em 1913 inicia o curso de Engenharia Civil pela Escola Politécnica, curso que ele só concluiu após vinte anos. Embora nunca tenha exercido a profissão de engenheiro, os conhecimentos matemáticos adquiridos em sua formação certamente o auxiliaram em sua docência e o diploma permitiu estender sua carreira docente ao Ensino Superior.

Nesse período, Júlio César de Mello e Souza também foi aluno da Escola Dramática Municipal, colega de turma de Procópio Ferreira. Apesar de não ter concluído o curso, utilizava a arte de interpretar em suas aulas.

Em 1925, Júlio César casou-se com Dona Nair de Mello e Souza, que fora sua aluna de Geometria na Escola Normal. Eles tiveram três filhos: Rubens Sérgio de Mello e Souza, Sônia Maria de Mello e Souza e Ivan Gil de Mello e Souza (SCOPEL, 2010, p. 22).

Sua carreira docente começou em 1913, ainda no colégio Pedro II. Deve-se ressaltar que nessa época a matemática ainda não era prioridade em sua carreira. Antes de dedicar-se à Matemática, Júlio César foi professor de História, Geografia e Física.

Como professor, Júlio César atuou Colégio Pedro II, na Escola Normal do Rio de Janeiro, na Faculdade Nacional de Educação (onde recebeu título de Professor Emérito), no Instituto de Educação do Rio de Janeiro e na Escola Normal da Universidade do Brasil. Lecionou no Serviço Nacional de Assistência aos Menores (SAM), uma entidade que atendia a menores carentes.

Júlio César criou uma metodologia diferente para ensinar matemática, e com esses métodos conseguiu revolucionar o ensino da época. Ele foi um caso raríssimo de professor que se tornou tão famoso quanto um ator de cinema, ou um jogador de futebol. A fama de sua 
metodologia se espalhou pelo Brasil, e ele realizou mais de duas mil palestras em território nacional.

Desde a infância Júlio César já mostrava seu gosto pela literatura, com os contos de seu manuscrito ERRE e com a sua "fábrica de redações" para vender aos colegas de internato.

Seus primeiros contos foram escritos por volta de 1918, quando ele começou a trabalhar no jornal $O$ Imparcial. Esses contos foram ao diretor Leônidas Rezende que os tratou com descaso, e deixou-os esquecidos num canto da mesa. Após algumas tentativas frustradas de publicá-lo, Júlio César retira-os da mesa do diretor, e os apresenta assinado com o nome de R. S. Slady, de nacionalidade norte americana, assumindo o posto de tradutor. No dia seguinte um dos textos estava publicado na primeira página do jornal. Esse episódio mostrou que para fazer sucesso como escritor era preciso uma grande mistificação literária.

Leônidas, aqueles contos que eu trouxe para você realmente eram muito fracos, não valiam nada, mas eu descobri um escritor americano formidável, que é muito curioso. Os contos dele são desconhecidos aqui no Brasil". Ele pegou o primeiro conto, achou interessante e botou: "Primeira página, risco dentro de um quadro, duas colunas". Quando, no dia seguinte, eu vi o conto de R. S. q Slady na primeira página do O Imparcial, dentro de um friso, duas colunas, limpo, eu raciocinei: "Que diabo! Então, quando é J.C.Mello e Souza, chumbo em cima! Quando é R.S.Slady, primeira página, duas colunas! (FARIA, 2004, p. 199)

Nos sete anos seguintes Júlio César dedicou-se em estudar os costumes, a cultura e a língua árabe, e escrever histórias com personagens orientais, ambientadas em desertos e cenários do oriente. Desde criança ele nutria profundo interesse pela cultura árabe. Seu livro preferido era As Mil e Uma Noites, que inspirou os primeiros contos de Salomão IV sua primeira mistificação literária no seu jornalzinho de infância ERRE.

Sabendo que um escritor brasileiro não faria sucesso assinando contos orientais com seu verdadeiro nome, Júlio César cria sua terceira e maior mistificação literária, o contador de histórias e escritor árabe, Malba Tahan. O nome Malba Tahan foi inspirado pelo nome de uma de suas ex-alunas, Maria Zechsuk Tahan.

Em 1925 Júlio César procura Irineu Marinho, com a ideia de surpreender o Brasil, inventando um escritor árabe que escreve contos educativos. Irineu Marinho era diretor A Noite, jornal mais lido no Brasil naquela época. Marinho, fundador da empresa que se tornou atualmente as Organizações Globo, aprovou a ideia e publicou uma série de contos assinados por Malba Tahan. O primeiro conto publicado pelo jornal foi Contos das Mil e Uma Noites. 
(...) e A NOITE lançou as histórias do escritor árabe Malba Tahan, morto em el-Riad, lutando pela liberdade de uma pequena tribo de beduínos perdida no deserto. Os contos eram publicados na primeira página e com excepcional destaque. Irineu Marinho, devo confessar, foi de uma ética impecável. Jamais revelou a pessoa alguma (nem mesmo ao Euricles) o segredo da mistificação literária da qual fora, não só cúmplice, mas o grande responsável. (FARIA, 2004, p. 200)

Como escritor, publicou mais de 120 livros, com autoria própria ou assinando como sua mistificação literária Malba Tahan. Seus livros tratam de matemática, didática, contos orientais, contos infantis, moral religiosa, teatro, temas brasileiros, etc. Sua obra preferida se chamava $A$ Sombra do Arco-Íris, porem a que se tornou mais famosa foi O Homem que Calculava, publicada pela primeira vez em 1939. Também escreveu em parceria com matemáticos da época, entre eles Euclides Roxo, Cecil Thiré, Célia Moraes, Jairo Bezerra.

Suas obras the renderam reconhecimento nacional, sendo ele agraciado com diversos títulos: cidadão sírio (honorário), cidadão honorário de Ubá (MG), cidadão de Queluz (SP) e da cidade de Itaocara (RJ); e também membro da Academia Carioca de Letras, da Associação Brasileira de Imprensa, da Associação Amazonense de Imprensa, da Sociedade Brasileira de Autores Teatrais, da Associação Brasileira de Educação, entre outros.

Júlio César de Mello e Souza faleceu no Recife em 18 de junho de 1974, vítima de um ataque cardíaco. Ele estava na capital pernambucana atendendo ao chamado da Secretaria de Educação do Estado para ministrar dois cursos no Colégio Soares Dutra, "A Arte de Contar Histórias" e "Jogos e Recreações". Seu corpo foi sepultado no Rio de Janeiro.

Com seus métodos, Júlio César conseguiu revolucionar o ensino da época, no entanto foi muito criticado e contestado pelos seus colegas de trabalho que eram tradicionalistas. Tinha muito carisma, e conseguia conquistar seus alunos com suas fabulosas histórias.

O professor Malba Tahan tornou-se um ícone da Educação Matemática no Brasil, tanto que foi atribuído ao dia 06 de maio, dia de seu nascimento, o dia da matemática no Brasil.

Somente após a criação de sua maior obra, O homem que calculava, que foi descoberta sua verdadeira identidade. Quem descobriu foi Rosalina Coelho Lisboa, por causa de um descuido do Júlio César que publicou o conto "Samulá, Contos Orientais", trocando o nome do tradutor para Radiales S. Este era um tradutor real, a referida poetisa entrou em contato com o tradutor e averiguou que se tratava de uma criação do professor Mello e Sousa.

Mesmo com a revelação de sua identidade, Malba Tahan já tinha alcançado fama e reconhecimento nacional e ganhado personalidade própria. Anos mais tarde, o presidente Getúlio 
Vargas autorizou o uso dos dois nomes, Júlio César de Melo e Sousa e Malba Tahan, na mesma carteira de identidade, criando assim seu heterônimo.

\subsubsection{A metodologia de ensino de Malba Tahan}

Entre os anos 30 e 70, período em que Malba Tahan teve sua maior produção intelectual e elaborou a maioria de suas obras, a matemática era uma disciplina extremamente difícil, basicamente apresentada em forma de teoremas e suas demonstrações, fazendo-se uso excessivo de simbologia.

Nessa época não era apresentada uma finalidade para o que se aprendia em matemática, a disciplina não estava vinculada com a realidade. Nesse contexto, surgem as propostas didáticas de Malba Tahan para o ensino e a aprendizagem de matemática que apresentavam uma matemática mais dinâmica e próxima do cotidiano do aluno, que partia do concreto para o abstrato.

A proposta de Malba Tahan era ensinar matemática de um jeito diferente, que despertasse o interesse do aluno. Em suas aulas ele trabalhava com estudo dirigido, manipulação de materiais concretos, matemática recreativa, jogos, enigmas, situações do cotidiano e histórias com os conteúdos (muitas vezes inventadas por ele).

Mello e Souza também defendia a criação de Laboratórios de Ensino de Matemática nas instituições educacionais e a elaboração de materiais concretos que auxiliem o aluno na aprendizagem de matemática para compor esse laboratório.

Ele forneceu mais de 60 sugestões de materiais didáticos, entre eles: jogos, materiais manipuláveis, filmes, transparências, problemas curiosos, cópias de atividades criativas, dispositivos, entre outros. Ele afirmava que o ensino partindo do concreto para abstrato, facilitava a aprendizagem. "O professor de Matemática, que dispõe de um bom Laboratório poderá, com a maior facilidade, motivar seus alunos por meio de experiências e orientá-los, mais tarde, com a maior segurança, pelo caminho das pesquisas mais abstratas.” (TAHAN, 1962, p.62)

Júlio César idealizava uma matemática mais atrativa e menos algebrizada, e criticou severamente a didática usada pela maioria dos professores na primeira metade do século XX. Ele mesmo já havia sido vítima dessa didática, quando estudava no Colégio Pedro II e seu boletim registrou notas vermelhas em matemática. 
Para ele, ensinar a matemática através de teorias difíceis, trabalhosas e que não tenha uma aplicação contribui para o desprezo dos educandos e não atribui a esta ciência uma utilidade prática. Aos professores que utilizavam essa didática ele denominava de algebrista.

\begin{abstract}
A meu ver, a desestima que há, pela nobre ciência dedutiva, é obra de um inimigo roaz e pernicioso; um inimigo que é para a matemática o que a broca é para o café, a lagarta para o algodão, e a saúva para todo o Brasil. Esse inimigo perigoso e implacável é o "algebrista". A denominação de "algebrista" é dada, em sentido pejorativo, a todo aquele que vive possuído da preocupação mórbida de complicar, enegrecer e lacerar a matemática. (TAHAN, 1961, p. 59)
\end{abstract}

Para diminuir a utilização abusiva da álgebra na Educação Básica e, melhorar a qualidade do Ensino de Matemática no Brasil, Malba Tahan, recomendava que fossem adotadas algumas medidas: revisão dos programas, apresentação analítica dos programas, regulamentação rigorosa das provas orais e escritas, supressão das unidades inusitadas, supressão dos problemas em falso e limitação do cálculo algébrico. (TAHAN 1961, p. 129).

Outra recomendação de Malba Tahan era o uso de jogos no ensino. Em seu livro Didática da Matemática Vol.II ( 1962) ele dedica cinco capítulos para esse tema. "O jogoo de classe, quando bem orientado e oportuno, é um dos recursos mais interessantes e mais eficientes a que o professor pode recorrer para obter a melhor e mais segura aprendizagem de seus alunos." (TAHAN, 1962, p. 180)

As idéias de Malba Tahan estavam muito a frente de seu tempo. Ao conhecer sua didática e suas ideias acerca do ensino de matemática percebe-se um certo profetismo de sua parte.

Nos dias de hoje a utilização das metodologias de ensino propostas por ele é recomendada pelas Diretrizes Curriculares de Matemática que orientam a Educação Básica no Estado do Paraná, e são pontos de discussão entre Educadores Matemáticos, tornando ele um precursor de muitas ideias que norteiam a Educação matemática atualmente.

Malba Tahan foi um precursor em tendências de educação matemática como: História da Matemática, Modelagem Matemática, Resolução de Problemas, e uso de tecnologias em sala de aula.

Em suas obras, principalmente nos dois volumes de Didática da Matemática (1961). Hoje essas abordagens metodológicas são recomendadas pelas Diretrizes Curriculares de Matemática.

Suas propostas didáticas só começaram a ser aceitas no Brasil com a criação dos primeiros núcleos de estudo de educação matemática na USP, UNICAMP, UNESP de Rio Claro e Universidade Santa Úrsula no Rio de Janeiro, em meados da década de 80, que recomendavam 
uma nova prática de ensino e aprendizagem de matemática, desvinculada da proposta de ensino que havia marcado o ensino de matemática no Brasil há muito tempo. (FARIA, 2004, p. 67-68)

Sobre a didática de Malba Tahan Lorenzato (1995, p. 97) afirma: "Sem dúvidas, ele se tornou um marco de nossa desprestigiada história da Educação Matemática brasileira". Algumas pessoas que conviveram e participaram de suas aulas afirmam que ele estava muito além de seu tempo, e que o resgate de seu modo de trabalhar talvez possa revolucionar o ensino atual no Brasil, e também eliminar várias repetências que acontecem pelo uso do método tradicional.

\subsection{DELINEAMENTO DA PESQUISA}

Tendo em vista que professores que atuam em Salas de apoio necessitam estar sempre em busca de métodos que facilitem a aprendizagem dos alunos, foi em uma sala de apoio a aprendizagem que esse trabalho foi realizado. A referida sala estava localizada no Colégio Estadual Rocha Pombo, situado no Município de Morretes- Pr, e era composta por alunos 20 alunos do $6^{\circ}$ ano da educação básica que apresentavam dificuldades para acompanhar o ensino nas turmas regulares, decorrentes das defasagens trazidas do ensino fundamental séries iniciais.

Nesse contexto, este trabalho busca apresentar as metodologias de ensino usadas pelo professor Malba Tahan em suas aulas como alternativa de trabalho a professores que atuam nas Salas de Apoio a Aprendizagem de Matemática, para que inspirados por Malba Tahan possam, com mais facilidade, auxiliar os alunos a minimizarem as suas dificuldades.

Teve como foco desenvolver um estudo investigativo sobre os métodos usados pelo Professor Malba Tahan em sua prática docente e aplicá-los como um facilitador de aprendizagem para alunos de Salas de Apoio a Aprendizagem de Matemática.

Primeiramente, após levantar os métodos propostos e usados por Malba Tahan para ensinar matemática, foi realizado um questionário com professores de matemática, investigando se eles conhecem Malba Tahan e utilizam sua didática em suas aulas.

Em um segundo momento foram investigadas as dificuldades apresentadas por uma turma de sala de apoio composta por alunos do $6^{\circ}$ ano da educação básica, e em seguida, foram aplicados três métodos propostos por Malba Tahan, a fim de facilitar a aprendizagem.

Ao final da aplicação foi realizado um questionário com os alunos para verificar se esses métodos são realmente eficazes e alcançam o objetivo proposto neste trabalho.

Quanto ao questionário aplicado aos professores, este, era composto de seis perguntas que tinham por objetivo saber se eles conhecem Malba Tahan e sua didática e se utilizam os métodos propostos por ele em suas aulas. 
Para isso foram coletados os dados de 24 professores de matemática da rede estadual de ensino do litoral paranaense, que atuam em diversos anos da educação básica. Da aplicação do questionário, pode-se perceber que 62,5\% dos entrevistados conhecem Malba Tahan e 37,5\% nunca ouviram falar dele. Com relação as metodologias propostas por Tahan, 87,5\% afirmaram não conhecer e apenas $12,5 \%$ tinham algum conhecimento.

Quanto a pergunta; "Você acredita que diferentes materiais didáticos e recursos metodológicos contribuem positivamente para a aprendizagem dos alunos?" apresentou como resposta unânime: "Sim, se bem utilizado".

As duas perguntas seguintes eram discursivas: "Você lembra o nome de algum livro de Malba Tahan?" e "Qual sua opinião sobre os métodos propostos por Malba Tahan para melhorar o Ensino de Matemática?".

A primeira obteve resposta positiva apenas de metade dos professores, todos citando o livro O Homem que Calculava como resposta. Apenas dois desses professores também citaram o nome de outros livros, um citou Matemática divertida e curiosa e outro citou Maktub e Didática da Matemática.

A última pergunta foi respondida apenas por três professores, ela perguntava a opinião dos professores diante das Metodologias de ensino propostas por Malba Tahan.

As respostas obtidas foram as seguintes: "Torna-se importantíssima diante da atual situação em que o ensino se encontra, com altos índices de reprovação e grande desinteresse dos alunos pela disciplina" ; "A utilização desses métodos facilitam a aprendizagem e ajudam o aluno a alcançar uma aprendizagem significativa" e "Esses métodos tornam a aula mais prazerosa e interessante para aluno".

Com a aplicação deste questionário foi possível perceber que o "educador" Malba Tahan e sua prática de ensino são pouco conhecidos pelos professores de matemática, que muitos conhecem apenas o seu lado escritor.

Mas que há um ponto em comum entre as concepções dos professores e as de Malba Tahan pois ambos acreditam que diferentes métodos de ensino contribuem positivamente para uma aprendizagem significativa.

Após a realização do questionário com os professores, foi realizada uma investigação sobre os conteúdos que estavam sendo trabalhados, conteúdos estes, que alunos mais apresentavam dificuldade nas aulas regulares.

No momento que foi realizada a pesquisa o aluno que estava sendo trabalhado tratava de frações e números decimais. Esses conteúdos geralmente se apresentam como um dos maiores problemas para alunos que estão nos sextos e sétimos anos do ensino fundamental. 
Pode-se constatar a dificuldade dos alunos com o conteúdo dos números decimais na pesquisa de ESPINOSA (2009, p.25) : “(...) parte dos alunos tem ideia do que seja um número decimal, mas poucos fazem apropriação do significado do conceito. A maioria dos alunos tem dificuldade de lidar com os decimais, suas representações e seu valor posicional."

A partir da entrevista com professores e com a pesquisa sobre as dificuldades dos alunos da sala de apoio, foram pensadas e elaboradas atividades utilizando os métodos de Ensino utilizados por Malba Tahan em suas aulas, como um recurso para facilitar a aprendizagem desses alunos. As atividades foram aplicadas nos dias 04 e 11 de dezembro de 2015 e contou com a ajuda da professora da Sala de apoio.

A primeira atividade, foi a construção de uma régua de frações, material de manipulação que ajuda na compreensão do conceito de fração. A aplicação desta atividade ocorreu em duas aulas de cinquenta minutos cada.

Vale ressaltar que dentro do que propunha Malba Tahan essa atividade pode ser considerada como aplicação do método do laboratório. Para o autor ao usar o método do laboratório “(...) o ensino da Matemática é apresentado ao vivo, com auxílio de material adequado à maior eficiência da aprendizagem. As demonstrações, os problemas, as equações, certos conceitos teóricos, são ensinados por meios de concretos. (TAHAN, 1962, p.61)

Para essa atividade foram utilizados canudinhos de refrigerante que seriam cortados formando assim o conceito de fração.

Após a confecção do material foram resolvidos alguns exercícios sobre comparação de frações e operações com frações. Essa atividade envolvia cálculos aritméticos buscando verificar se as atividades feitas com canudinhos estavam corretas.

Figura 2: Trabalho com os canudinhos
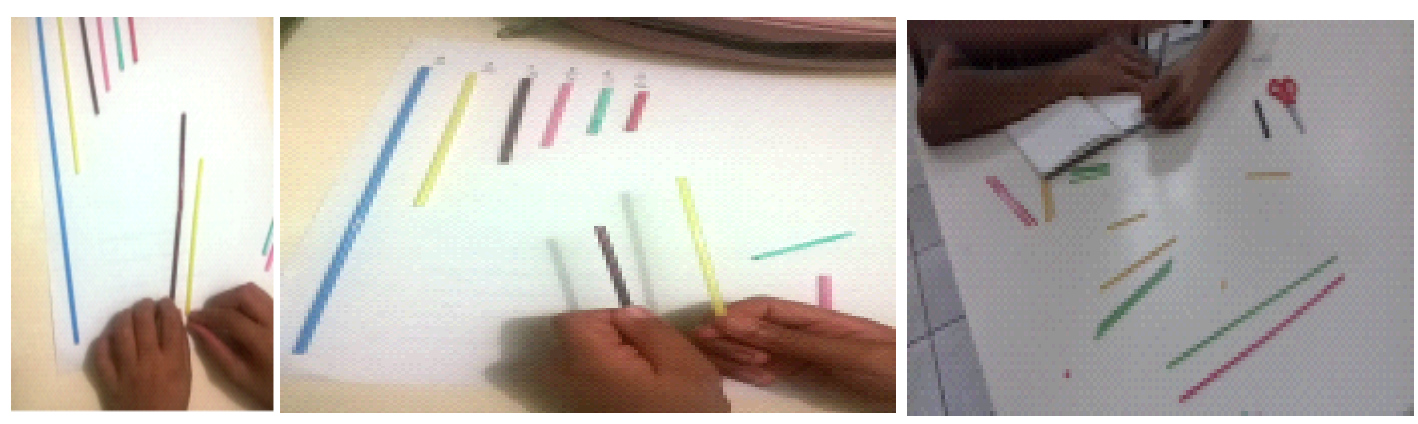

Percebeu-se que os alunos tinham muita dificuldade com este conteúdo e já concebiam uma ideia errada de que quanto maior fossem os números que formavam essa fração, maior seria a quantidade que ela representava (por exemplo: 1/5 era maior que 1/4 porque 5 é maior que 4). 
Quando foi inserido o uso do material concreto para resolver a atividade essa dificuldade desapareceu, dando lugar a um entusiasmo de querer aprender.

$\mathrm{Na}$ segunda atividade a proposta era trabalhar o conteúdo dos números decimais inserido no cotidiano dos alunos, mostrando uma ligação entre teoria e prática. "Malba Tahan pregava um Ensino de Matemática voltado para a formação do cidadão e, para isso defendia que este deveria ser vivo, mais humano e menos teórico" (SCOPEL 2010, p.46).

Para alcançar este objetivo foi trazido para a sala de aula o ambiente de um mercado, onde associava-se o preço dos produtos ao conteúdo trabalhado. Para essa atividade foram utilizadas duas aulas de 50 minutos.

Figura 3: Materiais utilizados na confecção da atividade

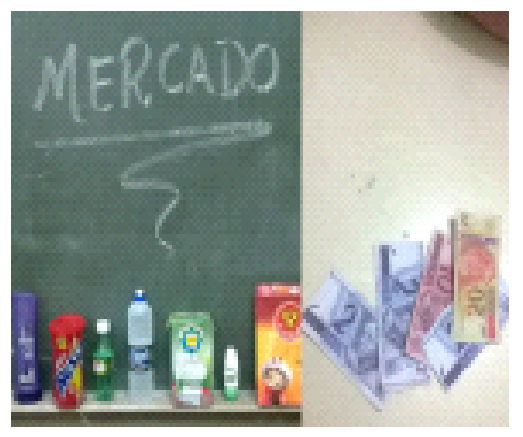

Os alunos foram divididos em dois grupos, um de clientes e o outro de caixas do mercado. Cada aluno do grupo dos clientes recebeu um envelope com uma quantia de dinheiro e duas listas de produtos, e precisava descobrir qual das duas listas seria possível comprar com a quantia disponível para ele.

Figura 4: Realização das compras

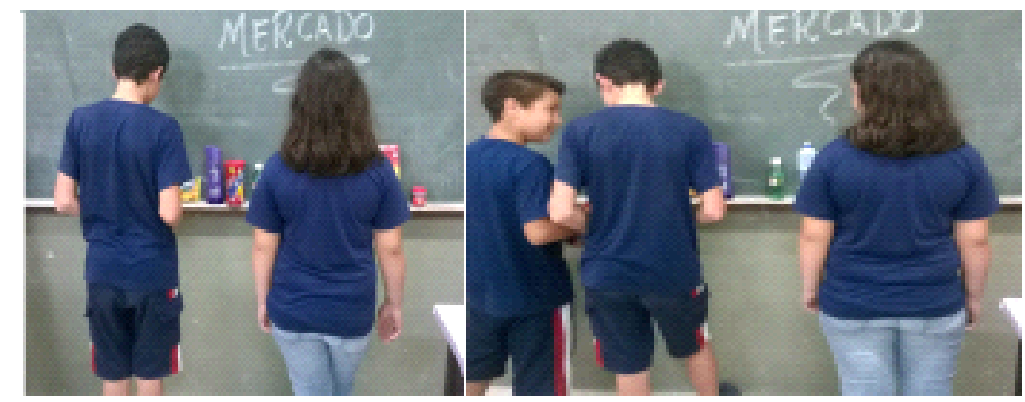

Após realizarem suas compras os alunos deveriam pagá-las no caixa. Encerradas as compras, invertemos os papéis dos grupos e realizamos novamente a dinâmica. Encerradas as dinâmicas, foi solicitado que os alunos demonstrassem como realizaram seus cálculos. 
A terceira atividade (também realizada no dia 11 de dezembro de 2015) foi o jogo dominó das operações, pois foi possível verificar com a aplicação das outras atividades que a turma apresentava muita dificuldade com as operações fundamentais, e isso acabava interferindo no seu desempenho nos outros conteúdos.

A utilização de jogos na aprendizagem também é proposta por Malba Tahan. Em seu Livro Didática da Matemática ele dedica grande parte do livro a esse tema.

Para a aplicação desta atividade foi utilizada uma aula de cinquenta minutos. No início foram explicadas as regras do jogo, que eram as mesmas do dominó tradicional e em seguida iniciou-se o jogo.

No começo do jogo os alunos apresentaram muita dificuldade para realizar as operações e precisaram de ajuda nos cálculos. No decorrer do jogo, conforme o tempo ia passando, as dificuldades diminuíram.

Figura 6: Alunos jogando dominó

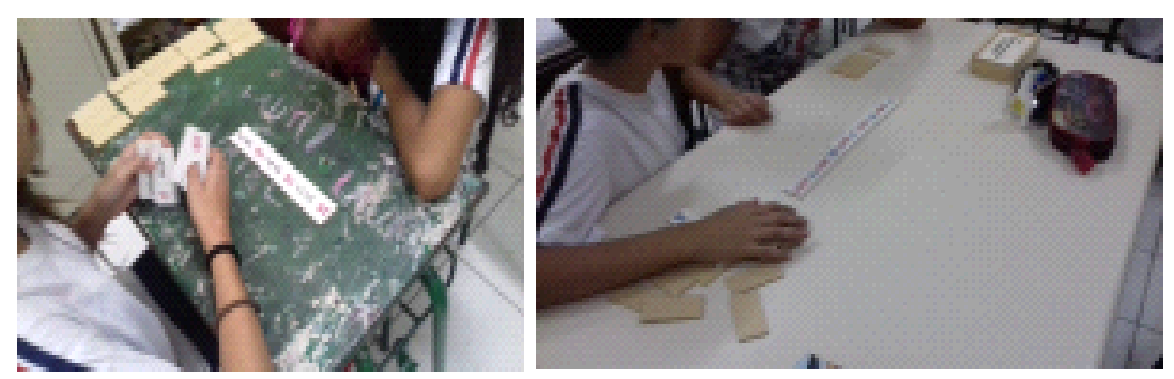

No transcorrer da aula os alunos conseguiram superar suas dificuldades e finalizar o jogo.

Para finalizar a aplicação foi realizado um questionário com os alunos, composto por três perguntas que buscavam avaliar se os métodos apresentados como facilitador de aprendizagem alcançaram o seu objetivo.

A primeira perguntava se alunos achavam que os métodos usados na aplicação facilitaram a sua aprendizagem, a segunda queria saber se eles gostaram de participar das atividades e a terceira solicitava que eles citassem o método que eles mais gostaram.

As respostas das duas primeiras questões foram unânimes: sim, eles gostaram de participar e acreditam que a atividade facilitou a aprendizagem. Já com a terceira questão pode-se perceber que a atividade preferida pelos alunos, foi o mercado (43,75\%), mas também percebe-se que todas as atividades obtiveram uma boa aceitação.

Com a aplicação dos questionários foi possível perceber que muitos professores conhecem Malba Tahan, mas que são poucos os que conhecem a sua didática. Mesmo sendo poucos, os 
professores que conhecem a prática educativa de Malba Tahan a consideram uma importante ferramenta para enfrentar as dificuldades encontradas no Ensino de matemática.

Em tempos de busca de novas práticas para o ensino e aprendizagem de matemática, torna-se importantíssimo conhecer a metodologia de ensino de Malba Tahan, educador que com esses métodos conseguiu fazer com que seus alunos aprendessem matemática de uma forma mais fácil e prazerosa.

Observando os acontecimentos no desenrolar da aplicação verificou-se que todas as atividades foram bem aceitas pelos alunos e que os mesmos foram bem participativos e entusiasmados durante toda a aplicação. Nesse contexto, é possível afirmar que as metodologias usadas por Malba Tahan em suas aulas ainda são eficazes para facilitar a aprendizagem dos alunos e com isso, melhorar a prática docente de professores em tempos atuais.

\section{CONSIDERAÇÕES FINAIS}

A matemática tem sido vista como uma vilã, como uma matéria difícil e que reprova. Não é raro encontrar em salas de aula de matemática alunos desmotivados, com pouco interesse, que não aprendem, que não gostam da matéria, e professores um pouco perdidos com relação ao seu trabalho.

Nos sextos anos esse quadro se intensifica, pois muitas vezes o aluno chega das séries inicias do Ensino Fundamental apresentando defasagens, e ao se deparar inúmeras situações novas o problema se agrava, dificultando a aprendizagem e impedindo que o aluno acompanhe seus colegas. Quando isso acontece esse aluno é designado por seus professores para as salas de apoio a aprendizagem, uma iniciativa do governo do Estado do Paraná para tentar diminuir as defasagens apresentadas pelos alunos.

Nas salas de apoio os conteúdos devem ser apresentados de uma forma diferente, que desperte o interesse do aluno e facilite sua aprendizagem, exigindo que os professores que atuam nessas turmas busquem metodologias que tornem o ensino mais fácil e interessante.

Em virtude dos fatos mencionados, o presente trabalho apresentou o professor Malba Tahan, como fonte de inspiração para professores de matemática, principalmente os que atuam em salas de apoio, para que baseados em suas ideias e metodologia de ensino possam alcançar um ensino mais eficiente.

Com esta pesquisa foi possível comprovar que ideias propostas por Malba Tahan há mais de 50 anos ainda são eficazes em salas de aula atuais, e que as mesmas podem ser utilizadas por professores que atuam em salas de apoio como uma ferramenta para tornar a matemática mais viva, lúdica e atraente. 
A aplicação deste trabalho demonstrou que os métodos usados por Malba Tahan em suas aulas estão aptos para serem utilizados em tempos atuais, trazendo resultados positivos para alunos que apresentam dificuldade em aprender a disciplina.

\section{REFERÊNCIAS}

ESPINOSA, C. E. Trabalho de Conclusão de Curso: Dificuldades e propostas para o ensino de números decimais da $5^{\circ}$ e $6^{\circ}$ séries. Universidade Federal do Rio Grande do Sul, 2009.

FARIA, J. C. de. Dissertação de mestrado: A prática educativa de Júlio César de Mello e Souza Malba Tahan : um olhar a partir da concepção de interdisciplinaridade de Ivani Fazenda. Universidade Metodista de São Paulo. São Bernardo do Campo, 2004. Disponível em http://www.malbatahan.com.br/artigos/dissertacao juracycfaria.pdf Acesso em 12 de maio de 2016.

FRANÇA, I. S. Programa Sala de apoio à aprendizagem em matemática: minimizando as dificuldades em busca da integração para os níveis do ensino fundamental. Pontifícia Universidade Católica, $\quad$ Curitiba, 2009. Disponível em http://www.pucpr.br/eventos/educere/educere2009/anais/pdf/2289 2153.pdf. Acesso em 02 de fevereiro 2016.

LAKATOS, E. M; MARCONI, M. de A. Metodologia cientifica: ciência e conhecimento cientifico; métodos científicos; teoria, hipóteses e variáveis. 7.ed. São Paulo: Atlas, 1988.

LORENZATO, S. UM (Re)Encontro com Malba Tahan. in Revista Zetetikè. Ano 3. No 4/1995. pp. 95 102.

PARANÁ. Diretrizes Curriculares de Matemática para a Educação Básica. Secretaria de Estado da Educação. Curitiba, 2008.

SCOPEL, A. J. C. Dissertação de mestrado: Contribuições didáticas de Malba Tahan para o ensino de matemática. Pontifícia Universidade Católica de Minas Gerais. Programa de Pós-graduação em Ensino de Ciências e Matemática. Belo Horizonte, 2011.

SOUZA, J. B. de M. Meninos de Queluz. Rio de Janeiro, Editora Aurora, 1949.

TAHAN, M. Acordaram-me de Madrugada. Recordações de um antigo aluno do Colégio Pedro II. Rio de Janeiro, Pedro II, 1973

.Didática da Matemática. Vol.I . São Paulo, Editora Saraiva, 1961.

.Didática da Matemática. Vol.II. São Paulo, Editora Saraiva, 1962. 